\title{
Culture as Suture: on the Use of "Culture" in Cross-Cultural Studies in and Beyond Intercultural Information Ethics
}

\author{
Thomas Taro Lennerfors $^{1}$ (D) Kiyoshi Murata ${ }^{2}$
}

Received: 4 November 2020 / Accepted: 24 March 2021 / Published online: 19 April 2021

(c) The Author(s) 2021

\begin{abstract}
Intercultural information ethics (IIE), a field which draws on the limits and richness of human morality and moral thinking in different societies, epochs and philosophic traditions as well as on their impact on today's social appropriation of information and communication technology, has been argued to lack an adequate theoretical understanding of culture. In this paper, we take a non-essentialist view of culture as a point of departure and discuss not what culture is, but what we (both in our everyday lives, and as researchers) do when we use the concept of culture. To do so, we look for inspiration in the concept of suture, a concept which means the thread which stitches, or the act of stitching, a wound, but has had a long and intricate journey within psychoanalysis and film studies concerning the issue of identification. Three understandings of the use of culture emerge: suture as cultural misidentification, the evil in the cultural suture, and multiple, repeated cultural sutures. We use these categories to diagnose the use of culture in IIE and beyond, and suggest that the use of culture as multiple, repeated sutures - in other words, a recognition that we constantly fail in describing culture or cultural differences, and that each suture is coloured by its conditions of production, and that we cannot but suture with culture anyway-might be a way forward for cross-cultural research.
\end{abstract}

Keywords Intercultural information ethics $\cdot$ Culture $\cdot$ Suture $\cdot$ Ethics

Thomas Taro Lennerfors

thomas.lennerfors@angstrom.uu.se

Kiyoshi Murata

kmurata@meiji.ac.jp

1 Division of Industrial Engineering and Management, Department of Civil and Industrial Engineering, Uppsala University, Box 169, 75104 Uppsala, Sweden

2 Centre for Business Information Ethics and School of Commerce, Meiji University, 1-1 Kanda Surugadai, Chiyoda, Tokyo 101-8301, Japan 


\section{Introduction}

While much research about the ethics of information and communications technologies (ICTs) has not paid sufficient attention to the context into which ICT is introduced, treating ICT reception in all parts of the globe as more or less similar to how it would be received in a "Western" country, for the last decades there is a stream of research-intercultural information ethics (IIE) - that does take cultural and national differences into account, arguing that "culture matters" [10]. What scholars within IIE show is that one can far from neglect culture-the values, beliefs, and practices of people-when discussing how ICT is received and translated into different cultural contexts, nor for creating a normative ethical basis for the acceptance or rejection of particular ICTs. Modern information technology brings people from all over the globe into contact in broader, deeper ways than many other elements of globalisation. Discussing culture in the context of information ethics is therefore crucial.

However, we also believe that the full potential of IIE is not yet fulfilled. A recurring problem that is identified within the field is ethnocentrism that despite years of scholarship remains "intransigent, if not predominant" ([10], p. 2). But more importantly, we will argue that the field relies on a too rigid understanding of culture, a concept that despite its central status within IIE scholarship has been argued to not be well explained nor discussed in depth [39]. As will be discussed in the subsequent part, the dominant theories of understanding culture within IIE seem to be those of Edward T. Hall and Geert Hofstede, which argue that people who belong to a certain country tend to share certain characteristics, as if they had a collective programming of the mind distinguishing them from other groups of people [20]. Such frameworks could be seen as essentialist, since they hold that people belonging to a culture share some sort of essence-a way of being, thinking, and acting - that distinguishes them from others. In contrast, and much more marginalised within IIE, there are non-essentialist frameworks that do not argue that culture is related to essences, but rather discuss how the concept of culture is used, how it is mobilized, how and why one identifies as a part of a culture $[8,28]$. Such non-essentialist understandings are a good counterweight to the overarching understanding of culture, which overemphasises the commonalities and downplays the complexities of cultures [39].

Inspired by the non-essentialist claim that culture is something we do rather than something we are, and sparked by a fascination with the concept of sutureliterally meaning the thread which stitches, or the act of stitching, a wound-we move beyond IIE and related fields to explore the notion of suture and if and how it can help us understand how we "do" culture, how we use the concept, how we mobilise culture in our everyday encounters and research. It is not farfetched to revisit the concept of suture since it has been used to make sense of the matter of identification. However, according to Žižek, although it was used as a defined concept within film studies, it has now lost its specific mooring in film studies and is used within the "deconstructionist jargon, functioning as a vague notion rather than a strict concept" ([48], p. 31). With an interest in returning 
to its theorization in film studies, to see whether the concept can be used more specifically than just 'closure' ([48], p. 31), we survey three distinct renderings of suture: (1) something which ties the viewer of a film to a character, (2) something which ultimately fails and exposes the evil behind its conditions of production, and (3) something which ties the viewer in fleeting encounters with different characters and their relationships in the film, recognising that the viewer will never fully identify with one character.

Through the use of these three interpretations of suture, we re-interpret how scholars in IIE and beyond have used cultural concepts, to understand better what we do when we meet with strangers in cross-cultural meetings, such as cross-cultural research. If culture is seen as suture, then we can argue that (1) the use of culture sutures someone to a certain culture, (2) the use of culture is not successful but exposes that the conception of culture that one is tying someone to is stained by the conditions of its production, exposing these conditions, and (3) the use of culture ties someone to a culture but at the same time acknowledges that this suture is temporary, coloured by its conditions of production and relationships between this someone and others, and that it is open to re-interpretations. We side with the third way of suturing with culture, arguing that its implications for research and practice are that we can perhaps not avoid suturing, but that each suture should be seen as an invitation to expose the conditions of its production, and de-suture, to eschew a sutured, complete, fixed understanding of culture, and a mere unveiling of the flawed and biased nature of cultural concepts.

The form of this paper follows the same explorative and tentative nature as the third way of suturing, not fully suturing the concept of culture to the concept of suture, but rather playfully exploring what the consequences would be if culture is regarded as suture. The text was produced within a project comparing the ethics and sustainability of ICT in Japan and Sweden, and the paper is thus shaped by these, and probably other, conditions of production. Before we turn to the concept of suture, we will give a brief description of the field of IIE, to which we tentatively suture this study.

\section{Intercultural Information Ethics}

Although one cannot deny that studies on the ethics of ICTs are often conducted in a Western context or based on Western concepts, since around two decades back, a stream of research has been emerging, called IIE. With associations and routes spanning UNESCO's First International Congress on Ethical, Legal and Societal Aspects of Digital Information, the Cultural Attitudes towards Technology and Communication (CATaC) conference, the International Center for Information Ethics (ICIE), the ETHICOMP conference and the CEPE Conference-Computer Ethics: Philosophical Enquiry, in the end of the 1990s, a discussion about the role of culture emerged related to the increasing penetration and spread of ICTs [4]. In Bielby's overview of the field, one of the early proponents Rafael Capurro is quoted at length. Capurro holds that there is a need for an IIE to critically discuss "the limits and richness of human morality and moral thinking in different societies, epochs and philosophic 
traditions as well as on their impact on today's social appropriation of information technology" (in Ref. [4], 236). In such a debate, it is important to keep an open mind, and have a patient and respectful dialogue between cultures. At last, Capurro maintains that:

"This is [...] an incentive to enlighten our minds and lives with regard to the open space of thought and the groundless world we share, which allow us to remain in an endless process of intertwining society, nature and technology, looking for flexible norms that regulate rather than block such a process" ([5]: 172, cited in Ref. [4], p. 237)

Throughout the history of the field of IIE, we have seen a number of empirical examples of how local cultures are resisting, or translating and modifying ICTs. Effectively debunking the idea of the Internet creating a global village, as Ess [9] with the use of Hjarvard [19] points out, rather than a global village, what will be created is a global metropolis with its different areas, connections, and movements. Within such a metropolis, there will be conflict and collisions. Ess [9] suggests: "more fruitful collusions can be documented in which persons and communities find ways to resist and reshape Western-based [computer mediated communications], so as to create new, often hybrid systems and surrounding social contexts of use that work to preserve and foster the cultural values and communicative preferences of a given culture" (p. 196).

Empirical examples illuminating the culture- and context-dependency of attitudes towards ICTs as well as the use of ICT are numerous. Apart from national studies of ICTs from all over the world, there are also a range of cross-national studies within the field, for example Murata's studies on attitudes towards Edward Snowden, which compared youngsters' attitudes towards privacy and state surveillance in eight countries [32, 34, 35], and Murayama et al. [37] which compared peer-to-peer software usage in Japan and Sweden. There are also a range of comparative studies based on the technology acceptance model (TAM) or variations of it. For example, Murata et al. [33] examined how ethical awareness, innovativeness perceptions and perceived risk influence the decision to become a cyborg or to use insideables, analysing whether cultures as different as those of Japan and Spain show different results. Furthermore, Fors and Lennerfors [14] and Majima et al. [29] studied the way (environmentally) sustainable ICT has been interpreted in Sweden and Japan respectively, and comparing those two papers, the interpretations are markedly different. For example, sustainable ICT was in Japan primarily constructed as an energy-saving technology, while in Sweden, there were also discussions about ethical and environmentally sustainable manufacturing and disposal of ICT. This was not explained as a cultural difference, but rather depending on the configuration of actors and networks in the different national contexts. When it comes to privacy, the right to which has always been considered to be posed a potential threat to by the development and use of ICT, various discussions have been made reflecting the differences among cultures (for example, [7, 22, 26, 27, 36]).

Apart from these more descriptive studies of how various technologies are received in different cultural contexts, there are also discussions about normative foundations for an IIE. Given that global communication technologies, global 
currencies, and global networks bring people living in different geographical parts of the world into more direct contact with each other, how should we reason about the normative foundations of the ethics of technology? Although the pure positions of universalism - that there is a given set of universal values - and relativism - that what is right in one part of the world is wrong in another-are theoretically interesting, Ess [11], Hongladarom [23], and others, are looking for a more pluralistic base where one can find connections between different culturally situated normative structures, that can together, complementing each other, create a normative platform for a global ethics. In such studies, it is pointed out that rather than just looking for differences, we can see similarities and complementarities, for example, between virtue ethics and the ethics of junzi [9, 24, 25], between phenomenological, feminist, and Watsuji Tetsuro's ethics [30]. Rather than obliterating cultural, historical, and traditional expression, we should seek an ethics that preserves these cultures, while at the same time seeks for ethical agreement in this global society-the pros hen (towards one) [9, 11].

In the above description of the field, we see a tendency towards separating the world into cultures with their respective cultural values that should be respected, and that for constructing a normative base we should be respectful of ethical systems belonging to the culture. Furthermore, as quoted in the introduction, there seems to be a tendency within the field (although not visible in the above description) towards ethnocentrism, meaning that not only are cultures different, but the culture that the first-person is belonging to is superior [10]. While it is easy to criticise ethnocentrism, the division of the world into different cultures with their own common values and practices, separating them from others, is also problematic. Elin Palm [39] argues that the field of IIE suffers from a lack of reflection on the very core concept it is building on, namely the concept of culture. She points out that to undertake meaningful comparisons of cultures, a better understanding of the key concept of 'culture' as well as of 'cultural' is needed. A main argument in Palm's paper is that the concept of culture is treated too simplistically and too homogeneously in the field of IIE, assuming that there are large groups of people sharing practices, values, and beliefs. By doing so, the field can sometimes risk running into stereotypical understanding of for example Western and Eastern understandings, while reality is more complex. A more nuanced understanding of culture is needed.

Still, from this overview of the field, the dominant notions of culture within IIE are essentialist. In contrast, we propose a conception of culture which is non-essentialist, arguing that what is most important is not what "culture" is but how people use "culture". So how is culture used in IIE scholarship and beyond? We believe that the notion of suture could help us understand how culture is used and why.

\section{Suture}

In everyday language, suture means "stitch", and is commonly used within medicine as the thread that holds bodily tissues together after a surgery or injury, or as a verb which concerns the act of stitching a wound. Theoretically, this concept was mentioned by Lacan, but not systematically used. For example, Bruce Fink 
describes that Lacan used the concept of suture when discussing the relationship between psychoanalysis and science [13]. Here, science is seen to "suture" the psychoanalytic subject, in other words, exclude it from its field, neglecting it. Lacan's disciple Jacques-Alain Miller [31] developed the concept, and argued that it was a fundamental part of Lacanian psychoanalysis. As explained by Žižek, suture for Miller designates the relationship between the signifying structure and the subject of the signifier ([48], p. 31), which one could interpret as the relationship between a symbolic, social system, and a person/subject in the system. Alain Badiou [2], who is influenced by Lacan, used the concept to explain how philosophy is becoming sutured to its conditions of truth, namely politics, science, love, and art. The main point is that philosophy, according to Badiou, has become too stitched to its different domains, and needs to de-suture itself and maintain independence while still being related to the domains. Suture, for Badiou, is therefore a term which indicates that something is tied down or connected to something in a way that does not unleash its full potential. Suture is "that reciprocal parasitism of philosophy and its conditions which periodically announces the weakening or abdication of thinking" ([3], p. XVIII). Although there is an intricate and dense argumentation by Žižek [49] about the positions of Miller and Badiou on the concept of suture, from now on we mainly follow the discussion of the concept in film studies where it has been used as a strict concept, going beyond the more general use of the concept as synonymous to 'closure' ([48], p. 31). This has provided three conceptions of suture, which will be explained in the following.

\subsection{Suture as Tying the Viewer to a Character}

In a pedagogic overview of the use of suture in film studies, Chaudhuri describes that suture is used in film studies to "describe the methods by which viewers are absorbed into the narrative and encouraged to identify with characters" ([6], p. 49). The technique of shot/reverse-shot, which will be explained below, is often seen as central to suture. Imagine that shot 1 is of a view of the sea. The shot follows the 180 degree rule which means that the camera can only capture the half circle in front of it. This first leads to a positive feeling of unbounded plenitude, but then arouses a sensation in the viewer-from what position or what gaze is the shot taken, "whose gaze controls what it sees"? ([42], p. 202). The camera bears the traits of a powerful symbolic father, with absolute knowledge, self-sufficiency, and discursive power ([6], p. 48), which the viewer is lacking. Therefore, shot 2 sutures this wound by locating a spectator in the other half of the field of vision, implying that the former shot was taken from the point of view of a figure in the narrative. Through this operation, Chaudhuri [6] describes, viewers of the film are 'stitched' or sutured into the subject-positions that the films make them have, which also makes them identify with the gaze of the person seeing. According to Chaudhuri "The healing of narrative can only happen after the wound has been inflicted, and the more wounded we are, the more desperate we become for meaning and narrative" ([6], p. 50).

In this notion of suture, there is a sense of miscognition, since the shot/reverseshot technique binds the viewer into a subject position ([40], p. 204). In the same 
way as the viewer misrecognises and is sutured into the narrative of the film, Silverman (and others) argues that this is at work more generally. For Lacan, misrecognition is the basis of the ego. This is formed during the Mirror Stage, where a child identifies with an image outside itself, usually its reflection in the mirror. Silverman argues that the child has the sensation of 'Yes, it really is me!' ([42]: 20). Chaudhuri explains:

To describe the infant's jubilant identification with its mirror image, Lacan uses the term 'captation', evoking the infant's 'capture' and 'captivation' by the imaginary. Captation also occurs when the subject identifies with other external images - including cultural representations. There, too, it (mis)recognizes itself. The Mirror Stage thus forms part of the series of misrecognitions through which the ego is constituted. It signals that the ego, which we think of as the core of identity or bearer of reality, is actually illusory. ([6], p. 108).

We see this misrecognition, where the viewer is tied to a certain subject position, as well as when a person is tied to a truth-claim about culture, as essential to this first understanding of suture.

\subsection{Exposing the Gaze of the Objective Shot}

Žižek revisited the concept of suture in the 1990s and 2000s, to argue for a renewed understanding of the concept. He claims that:

suture is the exact opposite of the illusory, self-enclosed totality that successfully erases the decentred traces of its production process: suture means that, precisely, such self-enclosure is a priori impossible, that the excluded externality always leaves its traces within-or, to put it in standard Freudian terms, that there is no repression (from the scene of phenomenal self-experience) without the return of the repressed ([48], p. 58).

A potential way to understand this is to look at a scene from Hitchcock's The Birds, which Žižek has discussed in a few Youtube videos. The birds have just attacked a gas station in Bodega Bay, California, and Melanie, the lead character, looks at when it catches fire. There is a series of standard exchanges with shots showing Melanie looking and shots of the fire spreading from a car until the whole gas station is on fire, a kind of standard procedure of suture (which sutures the viewer to Melanie). The next shot is then taken from above, a kind of God's view, which leads to a calm, objective, clear sense of the situation. But the situation changes. There is an ominous sound from the birds, and then we can see a bird entering the camera shot, and then one more, and it starts to seem like the objective shot was taken from the point of view of an evil, that beneath the seemingly objective shot, is pulling the strings. As Žižek says: "the shot which was taken as a neutral shot all of a sudden changes into an evil gaze, the gaze of the very birds attacking" (https://www.youtube.com/watch?v=sAiQciRjerA). This is what could be meant by sutures as not self-enclosed totalities. Rather than discussing the way in which the subject is sutured to a certain subject position, this second understanding concerns 
that the objective frame, the allegedly neutral shot, is itself sutured to a particular gaze, to some conditions of production.

\subsection{Suture: Fleeting Identifications with Different Characters in the Film}

Not fully content with either of these interpretations of suture, Richard Rushton in a recent paper proposes a third understanding of suture, which offers a way out of either the deception of suture, or the fact that suture will never work fully, but there will always be remainders [40]. He draws on political theory and Freud's ideas of joke work, and reaches an understanding of suture in cinema where the positions of identification - the sutures - shift and change throughout a film. The reason, he argues, is that rather than identifying with a specific character, the viewer identifies with a set of relationships between characters, in other words, what "characters to in relation to other characters, which decisions characters make or actions they perform in relation to other characters and to the story world more generally" ([40], p. 204). Any suture will thus always be temporary and open to the possibility to change. He explains:

"suture will fix the spectator at certain points in the unfolding of a film's story-suture is, after all, a matter of freezing or arresting the subject-but such fixing will never be definitive or totalizing. It will instead always be temporary and will adapt from moment to moment" ([40], 204).

From this point of view, suture takes a more temporary and flexible character, where subjects are sutured but that these sutures change over time.

Being inspired by these three formulations of suture, we will use them to interpret what we do when we use the concept of "culture" in IIE and beyond. In the Sect. 4 we connect the first understanding of suture discussed by Chaudhuri to culture. In the subsequent Sect. 5 we connect Žižek's understanding of suture to culture. In the Sect. 6, we link an understanding of suture inspired by Rushton to culture.

\section{Suture as Cultural Misidentification}

In this section, we discuss the various truth-claims that are done with respect to cultural identity in research and practice. In our everyday experience, we often use the concept of culture to compare and contrast different people, thus making claims about differences between the peoples in question. Such statements are ubiquitous, but perhaps taken to their extreme in the grand scale cultural frameworks that are used in cross-cultural research, where different cultures can be discussed in terms of a set of parameters. Such truth-claims seem scientific, measurable, and essentialist. These frameworks are popular, and so also in the field of IIE. In the context of Internet communication cultures, a special issue [12] discusses the merits and limitations of two such theoretical frameworks of culture, namely that of Hall and that of Hofstede. In his retrospective review of the CATaC conferences, Ess [10] explains how the theoretical resources of Hall and Hofstede have been a central point of reference. 
This is not to say that most agree with these frameworks, but they have become a common ground for discussing culture [10]. Furthermore, Palm [39] discusses the use of culture in IIE and Hofstede's framework alongside other frameworks which tend to essentialise cultural identity. Ess [10] and Palm [39] are good indicators that essentialism in the form of these frameworks is predominant within IIE. Before connecting these notions of culture to suture, we will briefly present the frameworks.

Hall discusses how cultures can have high context or low context, that they can be more or less monochronic or polychronic in terms of time concept, the speed of information spread amongst different cultures, and also relates to action chains (a process, task, or workflow from beginning to end), and particularly how willing a member of a culture is to complete or break action chains [17]. Seen from this perspective, Hall identifies Sweden as a low-context culture, while Japan is seen as a high-context culture [16, 17]. According to Hall, monochronic cultures include Germany, Canada, Switzerland, United States, and Scandinavia (including Sweden, of course), while Japan has a mixed relationship to time ([17], p. 18). In Japan, action chains can be broken while Americans "are brought up with a strong drive to complete action chains" ([17], p. 32).

Hofstede et al. [20] developed a theoretical framework that consists of several dimensions: power distance, individualism/collectivism, uncertainty avoidance, masculinity/femininity, long-term orientation, and indulgence vs. restraint. Countries are scoring higher or lower in these different categories. For example, there is more expectation and acceptance in Japan than in Sweden that power is distributed unequally. Sweden scores as a more individualistic country than Japan. Given Japan's score on masculinity and femininity, the gender roles seem more distinct than in Sweden.

Although these frameworks seem to have some explanatory power, the special issue by Ess and Sudweeks [12] as well as Palm [39] pointed to several shortcomings. First, it presupposes the existence of a rather homogenous national culture, while a nation can have a multitude of cultural expressions, belonging to different social practices. As Bielby [4] argues, there can be great religious, cultural, and philosophical diversity within the same region. Furthermore, even in the same tradition, as Wong states in regards to Confucianism, there are a variety of sub-traditions such as Neo-Confucianism and New Confucianism, "and, the problem of complexity multiplies once we consider Chinese culture as a whole, which is constituted by Confucian, Daoist and Zen, and each has their own moral systems" ([46]: 4). In terms of the individual vs. collectivism view, Teranishi [44] mentions the tradition of Japanese individualism which is somewhat different from Western one, and Japan's collectivist culture has been questioned by many [15, 43, 47]. Second, these frameworks neglect the hybridisation that comes from technological mediation-namely how communication over the Internet reshapes and changes culture. Although ICTs do not create a global village, there is a much more possibility for hybridization, new identities, and new cultural expressions than before. Furthermore, Hofstede's framework has oftentime been critiqued methodologically. When raising the view beyond IIE, a similar discussion is taking place within the crosscultural management literature, where apart from Hofstede's model, also the essentialist models of culture by Trompenaars and Hampden-Turner and GLOBE (Global 
Leadership and Organizational Behavior Effectiveness) research. And, the mentioned critique against these frameworks within IIE also exists within cross-cultural management [38].

Although there seem to be persistent discontent with these frameworks and quite radical critique against them, they are still used in cross-cultural research. Holliday [21] argues that although the problems of essentialism are accepted and critiqued, 'the temptation to be essentialist is quite deeply rooted in a long-standing desire to "fix" the nature of culture and cultural difference' ([21]: p. 6, In Ref. [38], p. 103). In line with the first understanding of suture, the nothing (the incomplete, undecided cultural identity) is replaced by something (something essentialist). Similarly to the psychoanalytic processes initiated in the mirror stage, one is quick to identify themselves or others with a complete mirror image: "Yes, this description really fits $\mathrm{me} / \mathrm{him} / \mathrm{her}$ !" If one turns to the theory of suture, why do we suture in this way? An explanation would be that one is quickly looking to suture the uncertainty and anxiety caused by facing something or someone unknown-a stranger coming from another "culture". One is then, in this interpretation of suture, content with the way in which the cultural suture covers over the lack, although when one thinks about one perhaps knows that these frameworks only partially captures what culture is. Perhaps one knows that the theory is not correct, but one identifies with the fiction to get closure. Such suture can be enacted in any practice, as individuals having to deal with those who are different, or as researchers trying to make sense of culture. We propose that this is what underlies Holliday's mentioning of a long-standing desire to "fix" the nature of culture and cultural difference. This fixing is suture in the first sense of the term.

\section{The Evil in the Suture}

In the second understanding of culture as suture, following Žižek, we will draw on the idea that the seemingly neutral, and objective point of view, is seen as the point of view of some external, ominous agent. The procedure of this second kind of suture is thus not that individuals, such as researchers, make truth-claims about culture, but rather that the seemingly neutral and objective view provided by such truth-claims, particularly with the most seemingly objective and neutral, such as Hofstede's, suddenly are reframed and become sutured to something evil.

An example of this is Galit Ailon's critical reading on Hofstede's book Culture's Consequences. She stresses that many cross-cultural analyses such as Hofstede's are skewed and biased in favour of the West, and in many ways represent "the non-West in ways facilitative of Western cultural hegemony, political dominance, and sense of positional superiority" ([1], p. 899). Although her critique is mainly directed to international management literature, where she quotes Westwood stating that crosscultural methods are "often reductionist, or else severely decontextualising, incorporating simplifying representational strategies that do violence to the inherent complexity of the social systems they pretend to represent" ([45]: 73, cited in Ref. [1], p. 899), it is important to heed to the warning also in the context of IIE. Apart from devaluing and misrepresenting "the Rest", Hofstede's text as well as others, 
according to Ailon, also overvalue the West: "Idealizing themselves, they construct self-images in a desired mold that, once mirrored, cracks under its own inconsistencies" ([1], p. 899).

Rather than suture as cultural misidentification, this understanding of suture ties truth-claims related to culture to its conditions of production. What is identified is how the theories, although seemingly objective, are not only potentially misrepresentative but also informed by a particular gaze that is not rendered explicit in the theories, but that can and should be exposed through critical readings. Perhaps, from the point of view of Žižek's understanding of suture, one could argue that it is the objectivity of the cultural frameworks that creates an eerie feeling of something not being right, that there is some evil lurking in the background.

\section{Multiple, Repeated Sutures}

For Rushton [40], there needs to be a third interpretation of suture. The first interpretation is tying the subject to a fixed position, while the second exposes the gaze that guides the suture. However, what Rushton looks for is a way out. A possible way out, which we develop with inspiration in Rushton's paper, is to see sutures as always temporary, always containing the conditions of production, and always serving as an invitation to de-suturing. This eschews both the first interpretation of suture which tells that we as subjects are duped, but also the second interpretation of suture, where we as subjects should expose and unveil the evil in its production. Rather, in this third form, we know that culture is a suture, not being too surprised by it, but rather approach these attempts to cover up as temporary and subject to re-interpretation. This could lead to a more playful and creative discussion about how we use culture, one in which we always expose the conditions of its production, suture again, and recognize that we constantly fail in describing culture or cultural differences.

This is as mentioned in the introduction based on a non-essentialist idea of culture. Rather than discovering things that pertain to our cultural identities, cultural identities are "the names we give to the different ways we are positioned by, and position ourselves within, the narratives of the past" ([18], p. 225). The positions, the strategic "cuts" of identity are always strategic and arbitrary, in a similar way to which the symbolic in Lacanian terms always fails to capture the whole of the Real ([18], p. 236). When doing cross-cultural research, we should thus not find what is similar or different but "which elements of difference do people articulate as important and when? Which facts do they highlight? What values do they attribute to difference? What is the discursive impulse that underlies their preoccupation with it?" ([1], p. 900).

The idea of multiple sutures proposes that we constantly suture, and perhaps we cannot help but suturing. However, we need to understand that all sutures are only temporary, and that they should be seen as an invitation to think again [41]. We need to understand that sutures are formed in relationships, as a result of the particular relationships and situations that we find ourselves in at the moment. In cross-cultural encounters, for example in research, there is a need for openness. Rather than 
contributing to a sedimentation of knowledge only, thinking about cultural difference as well as thinking in general is a way to attend to the moments when an idea, position, identity begins to repeat itself, and hardens into dogma.

With such a view of culture, another set of questions emerge: How is culture mobilised in different encounters and relationships on the micro-level? For example, why does culture or national identity become mobilised as a resource in a debate about ICT? How do we suture, and how can we adequately de-suture? How can our thinking about culture not harden into dogma and rather be flexible and open? When it comes to research about the cross-cultural, one needs to pay careful attention to the micro-processes that unfold. For example, it is likely that in a team of researchers from two countries, the researchers from one country are posited in a relationship where they are constructed as the experts of their particular country, and become representatives of it. This perhaps can lead to a situation where they are expected to have quite clear and distinct understandings of their own country and contrast them with the equally clear and distinct understanding of the researchers from the other country. This could lead to sutures as misidentification. Furthermore, in such research, it can become an aim in itself to find differences, because they are perhaps what seems particularly interesting - otherwise, what would be the idea of the crosscultural study? This relationship between researchers could then lead the researchers to fervently try to map out how different the countries are, which could perhaps even lead to exoticisation of native concepts. Rather we could see each suture as temporary, in which we always expose the conditions of its production, suture again, and recognize that we constantly fail in describing culture or cultural differences.

\section{Conclusions}

In this paper, we have advanced an understanding of how culture is or could be used within IIE, inspired by three different readings of the concept of suture. Based on the first understanding of suture - namely suture as cultural misidentification-we have also tried to explain the allure of essentialism, and why it is so such an easy recourse although one might know that it is not an accurate understanding of culture. The second understanding, which evokes and makes us expose the conditions of the production of cultural truth-claims, is also central to understand when we discuss a non-essentialist view on culture. In other words, each suture with culture is always from a certain often implicit gaze. Although the mentioned understandings of suture can to some extent diagnose part of the literature on how culture is used in everyday encounters and within research, we believe that the third understanding offers a more viable way forward. In the third understanding, culture could be seen as a series of sutures that are always incomplete, always formed by their conditions of production, and are invitations to further exploration. Such a perspective provides an alternative to the ethnocentrism and essentialism in IIE. The proposed idea of looking at culture as multiple sutures invites researchers to a quest to better understand the role of culture in IIE. It does not offer a quick-fix-a suture-but rather indicates a way forward that is hopefully more productive but also much more difficult and demanding to tread for the reasons discussed in the paper. Incidentally, 
another contribution is that this paper has hopefully shown that through a broad reading from various fields we can gain knowledge in compartmentalized debates in contemporary academia. On a meta-level, this paper is thus also a plea to de-suture understandings of culture, or other concepts, from particular subfields.

Acknowledgements The authors would like to express our sincere appreciation to Dr. Nina Kivinen and Dr. Annika Skoglund of Uppsala University for very helpful discussions in the early stage of the writing process. We would also like to thank Dr. Fareed Ben-Youssef of Texas Tech University, Dr. Mikael Laaksoharju of Uppsala University and two anonymous reviewers for their really helpful suggestions to improve this paper.

Funding Open access funding provided by Uppsala University. This study was supported by the JSPS (Japan Society for the Promotion of Science)/STINT (Swedish Foundation for International Cooperation in Research and Higher Education) Bilateral Joint Research Program "Information and Communication Technology for Sustainability and Ethics: Cross-national Studies between Japan and Sweden" (JPJSBP120185411 and JA2017-6999).

Open Access This article is licensed under a Creative Commons Attribution 4.0 International License, which permits use, sharing, adaptation, distribution and reproduction in any medium or format, as long as you give appropriate credit to the original author(s) and the source, provide a link to the Creative Commons licence, and indicate if changes were made. The images or other third party material in this article are included in the article's Creative Commons licence, unless indicated otherwise in a credit line to the material. If material is not included in the article's Creative Commons licence and your intended use is not permitted by statutory regulation or exceeds the permitted use, you will need to obtain permission directly from the copyright holder. To view a copy of this licence, visit http://creativecommons.org/licen ses/by/4.0/.

\section{References}

1. Ailon, G. (2008). Mirror, mirror on the wall: culture's consequences in a value test of its own design. Academy of Management Review, 33(4), 885-904

2. Badiou, A. (1999). Manifesto for philosophy. State University of New York Press

3. Badiou, A. (2003). On Beckett. Clinamen

4. Bielby, J. (2015). Comparative philosophies in intercultural information ethics. Confluence: Online Journal of World Philosophies, 2, 233-253

5. Capurro, R. (2008). On Floridi's metaphysical foundation of information ecology. Ethics and Information Technology, 10(2-3), 167-173

6. Chaudhuri, S. (2006). Feminist film theorists: Laura Mulvey, Kaja Silverman, Teresa de Lauretis, Barbara Creed. Routledge

7. Collste, G. (2008). Global ICT-ethics: the case of privacy. Journal of Information, Communication and Ethics in Society, 6(1), 76-87

8. Dahl, Ø. (2014). Is culture something we have or something we do? From descriptive essentialist to dynamic intercultural constructivist communication. Journal of Intercultural Communication 36. https://immi.se/intercultural/nr36/dahl.html

9. Ess, C. (2008). Culture and global networks hope for a global ethics? In M. J. van den Joven \& J. Weckert (Eds.), Information technology and moral philosophy. (pp. 195-225). Cambridge University Press

10. Ess, C. (2017). What's "culture" got to do with it? A (personal) review of CATaC (Cultural Attitudes towards Technology and Communication), 1998-2014. Routledge Companion to Global Internet Histories, 2017, 34-48. https://doi.org/10.4324/9781315748962

11. Ess, C. (2020). Interpretative Pros Hen Pluralism: from Computer-Mediated Colonization to a Pluralistic Intercultural Digital Ethics. Philosophy and Technology. https://doi.org/10.1007/ s13347-020-00412-9 
12. Ess, C., \& Sudweeks, F. (2005). Culture and computer-mediated communication: toward new understandings. Journal of Computer-Mediated Communication, 11(1), 179-191. https://doi.org/10. 1111/j.1083-6101.2006.tb00309.x

13. Fink, B. (1995). The Lacanian subject: between language and jouissance. N.J. Princeton Univ. Press

14. Fors, P., \& Lennerfors, T. T. (2013). Translating Green IT: The Case of the Swedish Green IT Audit. Proceedings of the First International Conference on Information and Communication Technologies for Sustainability (pp. 208-216)

15. Funabiki, T. (2020). Nihonjinron reconsidered. Kodansha (in Japanese)

16. Hall, E. T., \& Hall, M. R. (1987). Hidden differences:understanding the Japanese and how to do business with them. Anchor Press/Doubleday

17. Hall, E. T., \& Hall, M. R. (1990). Understanding cultural differences. Intercultural Press

18. Hall, S. (1990). Cultural Identity and Diaspora, in Rutherford, Jonathan (1990), "Cultural identity and diaspora." In J. Rutherford (Ed.), Identity: Community, Culture, Difference. (pp. 223-237). Lawrence and Wishart

19. Hjarvard, S. (2002). Mediated encounters. An essay on the role of communication media in the creation of trust in the 'Global Metropolis.' In G. Stald \& T. Tufte (Eds.), Global encounters: media and cultural transformation. (pp. 69-84). University of Luton Press

20. Hofstede, G., Hofstede, G. J., \& Minkov, M. (2010). Cultures and organizations: Software of the mind. McGraw-Hill

21. Holliday, A. (2011). Intercultural communication and ideology. Sage

22. Hongladarom, S. (2007). Analysis and justification of privacy from a Buddhist perspective. In S. Hongladarom \& C. Ess (Eds.), Information technology ethics: cultural perspectives. (pp. 108-122). Idear Group Reference

23. Hongladarom, S. (2016). Intercultural information ethics: a pragmatic consideration. In B. Jared \& K. Matthew (Eds.) Information cultures in the digital age: a festschrift in honor of Rafael Capurro. Springer, pp. 191-206

24. Lennerfors, T. T. (2015). The confucian ethics of Junzi in contemporary light capitalism. Taiwan Journal of East Asian Studies, 12(2), 287-308

25. Lennerfors, T. T. (2019). Ethics in engineering. Studentlitteratur

26. Lennerfors, T. T., \& Murata, K. (2019). Tetsugaku companion to Japanese ethics and technology. Springer Verlag

27. Lü, Y. H. (2005). Privacy and data privacy issues in contemporary China. Ethics and Information Technology, 7, 7-15

28. Långstedt, J. (2018). Culture, an excuse?-A critical analysis of essentialist assumptions in crosscultural management research and practice. International Journal of Cross Cultural Management, 18(3), 293-308

29. Majima, T., Udagawa, M., Yotsumoto, M., \& Lennerfors, T. T. (2017). Green IT did not take place: the translation of environmentally friendly IT in Japan. Journal of Information and Management, 37(2), 81-96

30. McCarthy, E. (2010). Ethics embodied: rethinking selfhood through continental, Japanese, and feminist philosophies. Lexington Books

31. Miller, J.-A. (1977). Suture (elements of the logic of the signifier). Screen, 18(4), 24-34

32. Murata, K., Adams, A. A., \& Lara Palma, A. M. (2017). Following Snowden: a cross-cultural study on the social impact of Snowden's revelations. Journal of Information, Communication and Ethics in Society, 15(3), 183-196

33. Murata, K., Arias-Oliva, M., \& Pelegrín-Borondo, J. (2019). Cross-cultural study about cyborg market acceptance: Japan versus Spain. European Research on Management and Business Economics, 25(3), 129-137

34. Murata, K., Fukuta, Y., Adams, A. A., \& Dang, R. (2017). How Snowden's revelations have influenced youngsters' attitude and behaviour in the PRC and Taiwan. Journal of Information, Communication and Ethics in Society, 15(3), 213-231

35. Murata, K., Fukuta, Y., Orito, Y., \& Adams, A. A. (2017). Few youngsters would follow Snowden's lead in Japan. Journal of Information, Communication and Ethics in Society, 15(3), 197-212

36. Murata, K., \& Orito, Y. (2008). Rethinking the concept of the right to information privacy: a Japanese perspective. Journal of Information, Communication and Ethics in Society, 6(3), 233-245 
37. Murayama, K., Lennerfors, T. T., \& Murata, K. (2010). Winny and the Pirate Bay: a comparative analysis of $\mathrm{P} 2 \mathrm{P}$ software usage in Japan and Sweden from a socio-cultural perspective. International Review of Information Ethics, 13, 20-25

38. Nathan, G. (2015). A non-essentialist model of culture: implications of identity, agency and structure within multinational/multicultural organizations. International Journal of Cross Cultural Management, 15(1), 101-124. https://doi.org/10.1177/1470595815572171

39. Palm, E. (2016). What is the critical role of intercultural information ethics? In Ethics and communication: global perspectives. In Collste, G. (Ed.) (pp. 181-195). Rowman \& Littlefield International

40. Rushton, R. 2017. Suture and Gus Van Sant's Milk, in Piotrowska, Agnieszka and Tyrer, Ben. Psychoanalysis and the Unrepresentable: From culture to the clinic (pp. 203-216). Taylor and Francis

41. Scott, D. (2005). Stuart Hall's ethics. Small Axe, 17, 1-16

42. Silverman, K. (1983). The subject of semiotics. Oxford Univ. Press

43. Takano, Y. (2008). The illusion of collectivism: The misconception in Nihonjinron and its origins. Shinyosha (in Japanese)

44. Teranishi, J. (2014). Religious foundations of economic behaviour in Japan. Keisoshobo (in Japanese)

45. Westwood, R. (2004). Towards a postcolonial research paradigm in international business and comparative management. In R. Marschan-Piekkari \& C. Welch (Eds.), Handbook of qualitative research methods for international business. (pp. 56-83). Edward Elgar

46. Wong, P. H. (2009). What should we share?: Understanding the aim of intercultural information ethics. ACM SIGCAS Computers and Society, 39(3), 50-58

47. Yamagishi, T. (2010). Wrong assumptions about Japanese Culture: The illusion of collectivist culture. Chikumashobo (in Japanese)

48. Žižek, S. (2001). The fright of real tears: Krzysztof Kieślowski between theory and post-theory. British Film Institute

49. Žižek, S. (2012). "Suture", Forty Years Later, in Hallward, P. \& Peden, K. Concept and Form, Volume Two. Interviews and essays on the Cahiers pour l'Analyse, Verso, pp. 147-168.

Publisher's Note Springer Nature remains neutral with regard to jurisdictional claims in published maps and institutional affiliations. 